\title{
Empresas públicas en el ordenamiento jurídico nicaragüense: régimen jurídico y replanteamiento actual
}

\author{
Amadeus Josué García Dávila ${ }^{85}$ \\ Universidad Centroamericana, Nicaragua \\ deus_9120@hotmail.com
}

Fecha de recibido: Noviembre 2016 / Fecha de aprobación: Diciembre 2016

\section{Resumen}

Uno de los temas hacia donde confluyen las más variadas concepciones terminológicas es el que versa sobre las entidades empresariales del dominio público que actúan bajo distintas formas jurídicas e intervienen económicamente en el mercado, participando directamente en el campo de la gestión económica. Nuestra realidad jurídica realiza pequeñas referencias en la Ley 550, "Ley de Administración Financiera y del Régimen Presupuestario", (2005), Ley 737, "Ley de Contrataciones Administrativas del Sector Público”, (2010), Ley 838, “Ley General de Puertos de Nicaragua”, (20I3), entre otras, sobre la existencia de empresas públicas. Sin embargo es necesario realizar un examen al ordenamiento jurídico existente sobre la base de los elementos que configuran la existencia y operatividad de las empresas públicas, desde su concepto hasta los elementos que sustentan al siempre vivo fenómeno empresarial. Para respaldar tal afirmación, los temas mencionados son estudiados sobre la base de una investigación documental argumentativa y sistemática en fuentes documentales legales, reglamentarias, y subsidiarias como la jurisprudencia patria y la comparada para finalmente formular propuestas claras de solución a los conflictos planteados por las normas y opiniones doctrinales en sí mismas, considerando su pertinencia en el estudio de las Ciencias Jurídicas y su replanteamiento actual.

\section{Palabras clave}

Empresa pública / intervención representativa económica / servicios de interés general / libertad empresarial

One of the issues to the confluence of the most varied conceptions is terminological which deals with business entities in the public domain operating under different legal forms and economically involved in the market, participating directly in the field of economic management. Our legal reality makes small references in Law 550, "Law of Financial Administration and Budgetary Regime" (2005), Law 737, "Law of Administrative Contracting of the Public Sector" (20 I0), Law 838," General Law of Ports of Nicaragua "(20 I 3), among others, the existence of public enterprises. However it is necessary to conduct a review to the existing law on the basis of the elements

${ }^{85}$ Abogado y Notario Público de la República de Nicaragua. Licenciado en Derecho y Máster en Derecho de Empresas con especialización en asesoría jurídica empresarial por la Universidad Centroamericana, UCA. Dedicado al asesoramiento empresarial a lo que respecta a constitución de empresas, contratación mercantil, entre otros. 
that configure the existence and operation of public enterprises, from concept to the elements supporting the ever-living business phenomenon. To support this claim, the above topics are studied on the basis of an argumentative and systematic documentary research in laws, regulations documentary sources, and subsidiaries and jurisprudence homeland and compared to finally make clear proposals for solving the conflicts posed by the rules and doctrinal opinions in themselves considering their relevance in the study of legal science and its current rethinking.

Public company / Economic representative intervention / Services of general interest / Entrepreneurial freedom

\section{Tabla de contenido}

Introducción. I. Consideraciones previas. 2. Concepto de la empresa pública. 3. La personalidad jurídica. 3.I. La personalidad jurídica de la empresa pública en el sistema registral. 4. Manifestaciones empresariales públicas. 4.I. El organismo descentralizado. 4.2. El organismo desconcentrado. 4.3. Sociedades anónimas públicas. 5. Fisura del principio de autonomía de la voluntad en el orden contractual, y la reducción del principio de libre competencia. 6 . Breve diagnóstico de la actividad empresarial pública en el ordenamiento jurídico nicaragüense 6.I Caso Produzcamos. 7. Régimen jurídico aplicable. 7.I Régimen jurídico de la contratación administrativa de las empresas públicas y replanteamiento. Conclusiones. Lista de Referencias.

\section{Introducción}

La intervencion económica del Estado en la economía es una realidad innegable. Por lo tanto el ejercicio de la potestad de iniciativa pública-económica supone toda una temática que involucra a distintas parcelas jurídicas para su análisis y apreciaciones. Al respecto nuestra coyuntura jurídica vislumbra problemas que van desde la naturaleza jurídica de las figuras que se crean bajo el concepto de empresa pública, su procedimiento de creación, funcionamiento y extinción, hasta las áreas de intervencion económica en que se desarrolla.

Los planteamientos vertidos en este trabajo de investigación, inician con los fundamentos técnicos jurídicos de la intervención representativa del Estado, su conceptualización que encuentra algunas menciones normativas desde distintos sectores donde el Estado se ha atribuido la potestad de crear empresas de forma heterogénea. Se prosigue con el planteamiento de los elementos que dan peculiaridad a la empresa pública como es la personalidad juridica, su forma de atribución y su forma de publicidad en el sistema normativo, las manifestaciones en que puede materializarse la empresa pública desde su aspecto subjetivo, las posibles fisuras existentes al principio de competencia entre los agentes económicos públicos y privados. 
Se plantean casos concretos donde se observa la problemática de la actividad empresarial pública, y se termina con el replanteamiento donde se apunta a considerar que el sistema normativo demanda un estatus legal claro sobre la creación, funcionamiento y extinción de la empresa pública para generar certeza en los actos en los que la administración pública ha intervenido tanto en el Derecho Privado, como en los aspectos que concierne a la Administración.

Por lo cual el trabajo en estudio, sobre la base de una investigación documental argumentativa y sistemática en fuentes documentales normativas, reglamentarias, y subsidiarias como la jurisprudencia patria y la comparada, tiene como objeto de análisis modular, la funcionalidad del Estado como empresario, en una economía basada en la intervención privada como gran protagonista, a través de figuras heterogéneas que no se ciñen a los límites dogmáticos construidos para la participación estatal en el comercio.

La contribucion que persigue este artículo de investigación reside en aperturar un nicho de nuevas investigaciones relacionadas pero no limitadas a la gestion de servicios públicos a través de entidades empresariales públicas, basando su estudio en los aspectos de constitución, funcionamiento, modificación y extinción de dichas actividades, valorando su potencial limitación en la economía, y los beneficios que genera su intervención en los aspectos jurídicos, económicos, políticos y sociales de nuestra realidad.

\section{Consideraciones previas}

Un nuevo y fructuoso campo de estudio e investigación nos ofrece la intervención económica representativa del Estado. De acuerdo con Castro Estrada (2002) la doctrina del Derecho Administrativo ignoró la teoría del servicio público a través de la intervención representativa del Estado en la economía, y no porque los servicios públicos hubiesen aparecido hasta entonces, sino porque las Ciencias Jurídicas no captó antes su existencia para sus estudios abstractos dentro del Derecho Público.

La doctrina del servicio público no ha sido acogida como doctrina universal. Los comentaristas alemanes y los italianos en general llegan a emplear ocasionalmente la expresión de "servicio público", pero no hacen del concepto un estudio particular, ni menos aún estructuran con él sus trabajos jurídicos sobre la Administración Pública y la forma de intervención representativa en la economía (Barrera Zapata, 1998).

Por ello la modernización o mejora de la gestión a través de la intervención representativa en la economía continúa siendo un tema de gran vigencia en la agenda de la reforma del Estado y su Gobierno. El caso latinoamericano para la empresa pública, según Morales (1990, p. 120), tiene un origen heterogéneo en cuanto a su formación, aseverando que los principales motivos para su creación son:

I. Suministro de los servicios públicos tradicionalmente prestados o controlados por el Estado;

2. Viejos monopolios coloniales; 
3. Nacionalizaciones en diferentes ramas y periodos;

4. Apoyo a la ejecución de políticas o planes económicos (actividades estratégicas o inexistente, necesarias para el desarrollo);

5. Compra de empresas privadas en quiebra para mantener empleo y producción,

6. Cubrir la falta de inversión privada,

7. Producir en aquellas ramas necesarias que, por su baja rentabilidad o alto riesgo de inversión ausenta al sector privado,

8. No injerencia extranjera.

Otro factor que alude la autora para el desarrollo del sector estatal empresarial, es la concepción doctrinaria e ideológica de la intervención pública, dada su vinculación a los cambios de estructura de poder, verbigracia de ello República Dominicana después de la caída de Trujillo, y Nicaragua después de la de Somoza (Morales, 1990).

Al respecto nuestra Constitución Política vigente (2014) establece a través del art. 103 que:

El Estado garantizará la coexistencia democrática de las formas de propiedad pública, privada, cooperativa, asociativa y comunitaria; todas ellas forman parte de la economía mixta, están supeditadas a los intereses superiores de la nación y cumplen una función social. (Cursiva es del autor).

Debe advertirse de lo expuesto que la noción y el régimen de la teoría del interés general en la prestación de servicios públicos, están indisolublemente unidos no solamente a la política económica del Estado en un momento dado, sino también a las concepciones sociales y económicas de cada época. Ello explica la diversidad de opiniones jurídicas que se han pronunciado en la materia. La doctrina francesa moderna y comparada de antaño había venido observando incongruencias y errores en el concepto de empresa pública como intervención del Estado, modificándolo frecuentemente para adecuarlo a una realidad que se empeñaba en contradecirlo (Rad Bruch, 1962).

Por dichas razones el abandono del principio de subsidiariedad significa que no es preciso buscar un específico fallo en el mercado para justificar la actuación de la iniciativa económica pública, y no parece que exista base constitucional suficiente para reintroducir por la vía de la distinta valencia del interés general, en cada caso, el principio de subsidiariedad, pues así ya la norma fundamental nicaragüense vigente (2014) establece a través del art. 5 que:

El Estado garantizará la existencia del pluralismo político, la economía mixta y el no alineamiento.

La economía mixta asegura la existencia de distintas formas de propiedad: pública, privada, asociativa, cooperativa y comunitaria; todas estas deben de estar en función de los intereses superiores de la nación y contribuir a la creación de riquezas para satisfacción de las necesidades del país y sus habitantes.

De modo, entonces, que debe reconocerse que la frontera de las soluciones sobre la intervención económica del Estado se encuentra construida a partir de la dilucidación de las incógnitas ¿Cuánto de mercado? ¿Por qué el Estado? y ¿Cuánto de mercado para el Estado?, ya que la evidencia empírica 
parece demostrar que las soluciones en la práctica no se inclinan hacia los extremos, y que ni un excesivo control de la economía, ni una mayor libertad de mercado son condición suficiente, cualquiera de ellas por separado, para propiciar un proceso de desarrollo económico armónico y sustentable (Barcelata Chávez, 1997).

\section{Concepto de la empresa pública}

En nuestro Derecho patrio la expresión "empresa pública” es una categoría prevalentemente doctrinal, que encuentra pequeñas referencias en cuerpos normativos como la Ley $\mathrm{N}^{\circ} 550$, "Ley de Administración Financiera y del Régimen Presupuestario", (2005), Ley 737, "Ley de Contrataciones Administrativas del Sector Público”, (20I0), Ley 838, “Ley General de Puertos de Nicaragua”, (20I3), entre otras.

El concepto de "empresa" encuentra algunas referencias en nuestro ordenamiento jurídico desde distintos aspectos:

Código del Trabajo de la República de Nicaragua (Ley 185, artículo 12, 1996):

Se entiende por empresa la unidad económica de producción, distribución y comercialización de bienes y servicios. Se consideran como parte de la empresa los establecimientos, sucursales creadas para el crecimiento y extensión de sus actividades siempre que no constituyan una persona jurídica diferente.

De acuerdo a Rojas Mercado (2010, p.20) la empresa como concepto jurídico puede encontrar dificultades en su conceptualización dado lo siguiente:

- La imposibilidad de obtener un concepto jurídico de empresa que posea contornos precisos.

- La imposibilidad de obtener un concepto jurídico de empresa que sea unitario y, por tanto, válido para todas las disciplinas jurídicas.

- Un concepto jurídico de empresa distinto del económico.

- Para el Derecho Laboral la empresa es una comunidad de trabajo y actividades.

- Para el Derecho Mercantil la empresa es una actividad económica del empresario, organizada profesionalmente dirigida al mercado.

- Para el Derecho de la economía simple, la empresa es una organización productiva.

Con relación a la "Empresa pública" se puede manifestar:

a) Alonso Ureba (1998, p.130I):

Unidades organizativas, dotadas generalmente de personalidad que con independencia de la forma jurídica que puedan adoptar, producen para el mercado bienes y/o servicios y que son creadas, dirigidas y/o controladas por la administración. 
b) Derecho Comunitario Europeo (80/732/CE, 25 de junio de 1980. Art. 2):

Son aquellos en las que los poderes públicos pueden ejercer, directa $\circ$ indirectamente, una influencia dominante en razón de la propiedad de la participación financiera o de las normas que las rigen.

De las definiciones ofrecidas desde distintas áreas se observa la aparente claridad del concepto económico de empresa, el cual se torna en oscuridad cuando se trata de acceder a un concepto de empresa uniforme y omnicomprensivo de la plural realidad que entraña el fenómeno empresarial. Lo que hace reflexionar que en nuestro sistema no existe un concepto claro sobre que es empresa ni mucho menos empresa pública, a pesar que para el caso en análisis ofrece una definición sobre empresa pública desde distintos cuerpos normativos, algunos únicamente nominándolo por todo el sistema jurídico, y otros ofreciendo una definición más elaborada.

A través de la Ley N 550 “Ley de Administración Financiera y del Régimen Presupuestario” (2005) que en su Art. 4, literal c, establece un concepto de empresas del Estado que dice:

Empresas del Estado. Son aquellos sujetos del dominio comercial del Estado que gozan de personalidad jurídica y patrimonio propios. Son creados por ley, la que determina los fines específicos (servicio público o actividad comercial) que dichas empresas deben perseguir así como el ámbito territorial al cual deban sujetarse. Excepcionalmente, podrán financiarse total o parcialmente con fondos del Presupuesto General de la República. Las empresas del Estado se sujetan al control tutelar de la entidad u organismo estatal al cual se encuentra adscritas.

Desde un punto de vista jurídico y económico resulta aparentemente complejo determinar la posible compatibilidad de esta previsión de la intervención de los poderes públicos en la economía con el proclamado principio de libertad de empresa en un sistema de economía de mercado, en el caso patrio una economía de mercado mixta. No obstante el artículo $104 \mathrm{Cn}$ establece que “...La iniciativa económica es libre" junto con el artículo 98 Cn que reza "La función principal del Estado en la economía es desarrollar materialmente el país..."

El reconocimiento expreso de la economía de mercado, como modelo económico, y de la libertad de empresa, como pilar toral del orden constitucional y derecho subjetivo garantizado por la misma, no implica o establece que el constituyente patrio haya optado por privilegiar de forma absoluta a la iniciativa privada sobre la iniciativa pública, ya que la misma Constitución ha introducido un concepto como es la economía mixta (art. 104) que involucra la función social como modulador de la libertad de empresa, trayendo como resultado la concreción del reconocimiento de la propiedad privada en el sector empresarial, y la intervención representativa del Estado en la economía como garante del principio de libertad de empresa, o su presupuesto fundamental, la libre competencia. (STCE 88/I96 del I de julio).

De esta doble titularidad del Estado nos encontramos también de que al ser un organismo económico a éste le es aplicable un régimen jurídico especial (Contrataciones, competencia, control, 
etc.). Por lo cual parecería contrasentido decir que como organismo económico se impone la aplicación del derecho común y como propiedad estatal es imprescindible la aplicación del Derecho público, lo cual no lo es, ya que lo que le da unidad y originalidad a la noción de empresa pública es la conciliación de dos regímenes jurídicos en la realización de tareas económicas de interés público, concepto que ha sido abordado con anterioridad (Nava Negrete, 1965).

Por lo cual se debe entender a la empresa pública como un organismo económico, coordinador de diversos elementos y bienes del Estado para producir bienes o servicios. Su carácter económico, que traduce la palabra empresa, exige su autonomía frente al Estado, pero la palabra pública debe traducirse en obediencia al Estado, quien la controlará y llevará su dirección.

\section{La personalidad jurídica}

Para el caso en análisis de la empresa pública es fundamental plantear la duda de Suan Rodríguez (1993), al esbozar de que sí es necesario o no que exista una persona jurídica independiente de la Administración para que pueda afirmarse la existencia de una empresa pública, porque si el titular es un ente público, como el Estado de Nicaragua, la cuestión es más dudosa y es preciso estudiar sí, para que exista empresa pública es consustancial la idea de personalidad jurídica.

La atribución de personalidad jurídica al Estado ha sido ampliamente aceptada por la doctrina y el derecho positivo, si bien distinguiéndose a veces entre personalidad jurídica interna y personalidad jurídica externa (López Guerra, 1980). En este mismo orden de ideas el tenor del artículo I del Código Civil de Nicaragua (1904) establece que: "Es persona todo ser capaz de ejercer derechos y contraer obligaciones...". Posteriormente clasifica la existencia de dos tipos de personas: naturales y jurídicas, definiendo a la segunda como: "Llámense personas jurídicas las asociaciones o corporaciones temporales o perpetuas, fundadas con algún fin o por algún motivo de utilidad pública, o de utilidad pública y particular conjuntamente que en sus relaciones civiles representen una individualidad jurídica." (Art. 3). A diferencia del Código Civil ecuatoriano, que por ejemplo en su artículo 585, al tratar sobre las personas jurídicas de Derecho Público se refiere en primer lugar a la Nación.

En este sentido nuestro ordenamiento jurídico a través de la Ley 550, artículo 4 literal c (2005), establece que las empresas públicas al ser del dominio comercial del Estado gozan de personalidad jurídica, sin embargo es importante denotar que la misma norma establece que es a través de Ley que deben ser creadas las empresas del dominio comercial del Estado, y es a través de ésta (ley) que se debe dotar de las características y fines que deben perseguir dichas empresas.

En palabras de López Guerra (1980) la teoría de García de Enterría y T. R Fernández puede resumirse en los siguientes aspectos en cuanto la personalidad jurídica:

- «La personalidad del Estado en su conjunto es sólo admisible en el seno de la comunidad de los Estados (...) Desde el punto de vista del ordenamiento interno no aparece en cambio esa personalidad un tanto mística del Estado, sino sólo la 
personalidad propiamente jurídica de uno de sus elementos: la Administración pública» (pág. 29).

- «El Parlamento, más que órgano del Estado, es un órgano del pueblo, auténtico titular de 'la propiedad del poder'» (pág. 29).

Claro está que en el caso del empresario público dicho concepto legal (Código de Comercio vigente) deberá ser aplicado en la medida en que este ejerza actividades mercantiles. Pero para la materia acá en estudio, es sumamente necesario que el empresario público goce de personalidad jurídica derivada de la Administración. Por lo cual, la duda planteada por Suan Rodríguez, de sí la empresa pública debe poseer personalidad jurídica derivada expresamente de la administración pública, y no utilizar la misma, la respuesta es sí. Dado que es necesario que la voluntad representativa del Estado (Asamblea Nacional) derive solemnemente la personalidad jurídica de la Administración desde su aspecto interno para poder permitir que la misma Administración intervenga de forma directa en la economía. Sin embargo la realidad práctica demuestra deficiencias al momento de establecer la atribución de personalidad jurídica, dada la disparidad de las figuras utilizadas por el funcionario público al constituir una empresa del Estado, ejemplo de ello es la configuración empresarial municipal.

\section{I. La personalidad jurídica de la empresa pública en el sistema registral}

Paralelo a ello, la calificación registral a las personas jurídicas creadas por la ley es un tema sumamente complejo que se intentará plantear, dado que al nacer con independencia del Registro surge un conflicto entre los efectos que brinda la publicidad registral frente a la legal.

En líneas generales la inscripción de todo acto o derecho deberá ser objeto de la evaluación realizada por la institución registral correspondiente la que determina el acceso al registro de los actos y derechos que además de tener relevancia registral cumplan con los requisitos legales. Pero la existencia de este tamiz encaja en la búsqueda de la eficacia plena de la publicidad registral. Así el Estado además de regular lo que tendrá relevancia frente a terceros (como regulador), otorga a los participantes las herramientas para que puedan conocer todo lo que ha accedido al registro bajo el cumplimiento de legalidad y seguridad jurídica (como garante) (Campos Fernández, 2013).

Como es de verse tratándose de la publicidad registral, la inscripción y los medios para dar a conocer lo registrado constituye punto de partida para generar los efectos de oponibilidad, legitimación y fe pública; sin embargo tratándose de la publicidad legal, será la publicación en el Diario Oficial la que consolide la existencia de la persona jurídica y además la presunción de su conocimiento (Campos Fernández, 2013).

En este sentido el profesor Gerardo Eto Cruz (s/f, p. 263) manifiesta:

La voluntad del Estado expresada en la ley, pasa pues inexorablemente por un requisito esencial para su obligatoriedad; $y$ esta es la publicación. Es imposible imaginarse la voluntad del Estado que 
solo obligue a los ciudadanos a cumplir la ley si es que esta no es formalmente conocida vía la publicación. En este sentido, el sigilo legislativo, o las leyes secretas, se reputan de plano inconstitucionales. Con la publicación de la norma, se produce en el sistema jurídico los efectos vinculatorios de la norma y preceptos jurídicos, pues la voluntad del Estado "perfecciona" con la publicación.

Por lo que se puede afirmar que si bien la inscripción registral no constituye un elemento del acto constitutivo en estos casos, si lo será la publicación de la ley en La Gaceta Diario Oficial la que otorgará la personalidad jurídica dotando de eficacia a la empresa pública (art. 4 literal c, Ley 550), además de los fines que perseguirá, su forma de administración y características propias. Sin embargo, tratándose que la calificación de los actos referidos a las personas jurídicas creadas por ley es un tema significativo, es necesario señalar que la inscripción que se realizará en el Registro Público, ya sea por mera voluntad del funcionario público, es esta meramente declarativa y por tanto, no es consustancial el registro de la misma para su plena eficacia.

Pero vale decir que al ser voluntaria el sometimiento a la publicidad registral, una vez que se decida inscribir para los fines declarativos la creación de la empresa pública, se tendrán los actos posteriores que pasar por el filtro de la calificación de legalidad que realiza el registrador (Campos Fernández, 2013).

Análogamente cabe preguntarse ¿Por qué se requiere la inscripción de los actos posteriores? Lo cierto es que admitir la tesis contraria de no inscripción posterior de los actos implica que la empresa pública pueda acceder al registro con actos que no hayan sido otorgados respetando la voluntad soberana expresada en su ley creadora. Pues una vez registrado el acto constitutivo por manifestación voluntaria del funcionario, existirá un sometimiento a los principios registrales, tales como: el principio de rogación (art. 32), legalidad en su aspecto formal (art. 35), tracto sucesivo (art. 30) legitimación, todos ellos establecidos en la Ley $\mathrm{N}^{\circ} 698$ "Ley General de Registros Públicos” (2009).

\section{Manifestaciones empresariales públicas}

El servicio público económico que realiza la empresa pública, es a través de una personalidad jurídica y con un patrimonio propio, en conjunto con su estructura administrativa la hace formar parte de la Administración Pública en general, pero su autonomía le permite actuar separadamente. Funciona con una personalidad distinta de la Administración Pública (teoría interna de la personalidad del Estado) y sus operaciones se apoyan en un patrimonio propio, sin que su presupuesto forme parte general del Estado (artículo 4, Ley $N^{\circ} 550,2005$ ). Pero su autonomía y funciones económicas no rompen con la unidad de la administración, pues logran armonizar con ella en virtud de estar vinculada con el Estado a través de la tutela económica que éste ejerce sobre aquélla (Nava Negrete, 1965). 
4.I El organismo descentralizado por servicio en su concepción originaria teórica y legislativa se ocupaba exclusivamente de servicios de orden administrativo: defensa exterior e interior, educación, justicia, salubridad, caminos, etcétera

Nuestro ordenamiento jurídico define al organismo descentralizado a través del art. 4 párrafo 3 de la Ley N²90, Ley de Organización, Competencia y Procedimientos del Poder Ejecutivo (20I5) como:

Descentralización Administrativa, es una forma de organización administrativa en la cual se confiere a través de una Ley a un órgano, autonomía técnica y administrativa. Se le otorga patrimonio propio y personalidad jurídica, existiendo control o tutela del Presidente de la República o del Ministerio al que estén vinculados. El Director del ente es nombrado por el Presidente de la República o por la autoridad establecida de acuerdo a su Ley Creadora.

Derivada de esa realidad la empresa pública, de exclusiva propiedad pública u organismo descentralizado, a pesar de ser un organismo público con que incluso forma parte de la Administración Pública, y de prestar indudablemente un servicio público, su régimen jurídico no es únicamente de Derecho Público ya que no excluye en muchas de sus actividades al derecho común (Nava Negrete, 1965).

Verbigracia nacional:

- Ley 838 “Ley General de Puertos de Nicaragua” (2013):

Art. 5 Definiciones, numeral 18:

Empresa Portuaria Nacional EPN: Es la autoridad administradora del sistema portuario nacional estatal. Es el ente de derecho público descentralizado, con carácter autónomo, del dominio comercial del Estado, adscrito a la Presidencia de la República, con personalidad jurídica, patrimonio propio y capacidad plena para ejercer derechos y contraer obligaciones, administrador de los puertos de su propiedad, en administración y los contratos de los puertos concesionados por el Estado de Nicaragua según procedimiento de esta Ley.

Para el caso de lo preceptuado en el artículo 4 literal c de la Ley 550 (2005), el ejemplo aquí en análisis puede ser sujeto al siguiente test de control en referencia al tenor:

i. Aspecto personal de la Empresa: De acuerdo a lo establecido en el artículo 4 literal c de la Ley 550 (2005), el legislador no estableció la figura que corresponderá al aspecto formal de la empresa pública, lo cual trae como consecuencia heterogeneidad al momento de establecer este aspecto.

En este sentido la Ley 838, "Ley General de Puertos”, establece que la autoridad administradora del sistema portuario nacional estatal es un ente de derecho público descentralizado.

A diferencia de la Empresa Nicaragüense de Acueductos y Alcantarillados Sanitarios que es una entidad estatal de giro comercial. 
ii. Aplicación de un régimen jurídico ecléctico: Fin específico de la empresa (servicio público o actividad comercial) artículo 4 literal c de la Ley 550 (2005).

En este sentido el párrafo infine del artículo 19 de la Ley 838, establece:

“La EPN se regirá por la presente Ley, sus reglamentos, acuerdos de la Junta Directiva y en lo que no estuviere previsto en ellos, por las demás leyes del país y las normas de los convenios internacionales en materia marítima portuaria en los que el Estado de Nicaragua sea parte.”

Lo cual abre una interrogante, la Empresa Portuaria ¿Es una empresa concurrencial o no concurrencial? Dado que de acuerdo al precepto del artículo antes citado, le son aplicable las demás leyes de la República, tales como la Ley 737, Ley de Contrataciones Administrativa del Sector Público en tanto a su control en la contratación administrativa y su posible exclusión a esas determinadas reglas (ver artículo 2 numeral 6 de la Ley), reglas mercantiles (Código de Comercio de Nicaragua), entre otros.

Personalidad jurídica propia: reconocimiento expreso de personalidad jurídica de la Administración (personalidad jurídica interna del Estado).

Art. 5.18, Ley 838: ... Es el ente de derecho público descentralizado, con carácter autónomo, del dominio comercial del Estado, adscrito a la Presidencia de la República, con personalidad jurídica, patrimonio propio y capacidad plena para ejercer derechos y contraer obligaciones...

En ese mismo orden de ideas, es importante remitir el análisis a lo establecido en la Ley General de Puertos de Nicaragua, específicamente en su artículo 23 de funciones y atribuciones de la EPN que en su numeral 26 establece que:

Proponer al Presidente de la República para su autorización, la creación de las empresas que sean necesarias para el cumplimiento de los fines y objetivos de la EPN;

Tenor que a la luz del análisis del tema en estudio sería objeto de un desmedido examen para comprender los alcances de aplicación de dicho mandato, pero que para los fines que acá se buscan se postulan las siguientes ideas preliminares:

a) La autorización del Presidente de la República para la creación de empresas por parte de EPN, ¿trae consigo revivir la teoría de la "Zona de reserva normativa para la Administración"?

b) Dicha "Zona de reserva normativa para la Administración" establecida por el tenor mencionado, entraría en conflicto con lo estipulado en las funciones otorgada constitucionalmente a la Asamblea Nacional.

c) La creación de empresas con la autorización del Presidente de la República para EPN, ¿son empresas concurrenciales o no concurrenciales? 
d) Los beneficios tributarios que establece la Ley de Concertación Tributaria para EPN, artículo 32.2 Ley de Concertación Tributaria, ¿son aplicables a las empresas creadas por EPN, todo esto en estricto sentido al principio sustancia sobre forma?

Cabe aclarar que en nuestros días el servicio público se presenta por organismos públicos o privados y su régimen puede ser público o privado e incluso mixto. Decir ahora servicio público no obliga a pensar necesariamente en un régimen jurídico especial y en un organismo público (Nava Negrete, 1965).

De ahí nuestra jurisprudencia Contenciosa administrativa establece:

Todo prestador de servicio público... se constituye en un AGENTE del Estado por estar encargado de prestar el Servicio Público... en principio corresponde al Estado realizarlo, pero que por mandato directo de éste lo delega mediante Concesión. (SCSJN No.03 Managua, veinticinco de enero del año dos del año dos mil once.)

Por lo cual vale decir que dentro de las entidades públicas estatales (Administración Descentralizada) coexisten tanto las formas jurídicas llamadas puras, con un régimen típico de Derecho Público, con aquellas entidades descentralizadas que realizan actividades industriales y comerciales, dotadas de un régimen jurídico mixto de Derecho Público y Privado.

4.2 El organismo desconcentrado: la desconcentración implica la delegación de competencias al interior de una dependencia o entidad pública. El instrumento legal para llevar a cabo la desconcentración es la delegación a través de acto administrativo de la máxima autoridad institucional, siempre que la norma aplicable lo permita.

En este sentido nuestro ordenamiento jurídico define al organismo desconcentrado a través de la Ley $N^{\circ} 290$, Ley de Organización, Competencia y Procedimientos del Poder Ejecutivo, en su artículo 4, párrafo 2, como:

Desconcentración Administrativa, es una forma de organización administrativa en la cual un órgano centralizado confiere autonomía técnica a un órgano de su dependencia para que ejerza una competencia limitada a cierta materia $\circ$ territorio. El ente gubernamental que tiene administración desconcentrada no tiene patrimonio ni personalidad jurídica, su status legal y presupuesto devienen del Ministerio al que están vinculados jerárquicamente.

4.3 Sociedades Anónimas Públicas: son sociedades mercantiles que puedan adoptar formas empresariales, es decir que se trate de una unidad básica de producción, en sentido amplio, y por otro, estar controlada por el sector público, ya sea por tener este más del $50 \%$ de su capital o por estar, de hecho, contralada por éste (Arenas Alegría, 2013).

Verbigracia: El quince de julio de mil novecientos noventa y tres, se constituyó la Empresa Correos de Nicaragua, mediante Escritura Pública número siete (7) de Constitución Social y Estatutos, como sociedad anónima, autorizada ante los oficios notariales del Doctor Manuel 
Cordero Sanhueza (q.e.p.d.) y debidamente registrada en el Registro Público Mercantil de Managua. Adquiriendo de esa manera su personalidad jurídica y patrimonio propio, lo mismo que autonomía para brindar el servicio postal, en sus distintas categorías y modalidades.

Empero de lo anterior es importante plantear si esa fórmula de Sociedad Anónima Pública (en su momento) era posible bajo los postulados establecidos en el Derecho Mercantil nicaragüense. Por lo cual se tiene a bien considerar:

- En Nicaragua el artículo 202 del Código de Comercio (19/4) no admite la existencia de la unipersonalidad en la sociedad anónima de forma originaria. Por lo cual la existencia de una sociedad anónima pública bajo el escenario expuesto, se confronta claramente con la regulación normativa expuesta. Será hasta en la entrada en vigencia del proyecto de Código mercantil que se admitirá la unipersonalidad de forma originaria en las sociedades de capital (ver Artículo 2110-26 del Anteproyecto).

- Se rompe con el elemento patrimonial de la sociedad de capital y su división accionaria (Art. 224 Código de Comercio).

- La calificación registral contraviene con lo dispuesto en el Código de Comercio con relación a la forma de constitución de sociedades mercantiles.

- No hay un criterio armónico sobre el elemento subjetivo de la empresa pública.

- A través de la Ley N 758 "Ley General de Correos y Servicios Postales de Nicaragua" (20I I) lo dispuesto en el art. I I 5 de la Ley $N^{\circ} 200$ se reforma, estableciendo que Correos de Nicaragua es “...una entidad de derecho público de carácter estatal y de servicio público, de giro comercial, con personalidad jurídica propia, de duración indefinida y patrimonio propio...”.

Se comprende, por lo tanto, que el criterio de "empresa pública" no sirve para manifestar toda la gama posible de empresas en sentido económico (actividades civiles, industriales o comerciales) ante la falta de coincidencia entre los conceptos público y estatal. Pero, aunque resulta impropio definir como "empresas públicas", ni siquiera en su acepción más estricta (posiciones doctrinarias), a las manifestaciones expuestas que son propiedad total del Estado o de participación estatal mayoritaria, no se puede desconocer que se trata de una terminología jurídica que ha terminado por imponerse en el plano de la realidad, y que merece un análisis profundo sobre su materialización y ejecución.

Lo cual refleja que nuestra legislación aún no encuentra claridad sobre el concepto de empresa, y mucho menos sobre la configuración dogmática y funcional de la misma, añadido a la disputa jurídica de que personalidad jurídica del Estado no es igual a personalidad jurídica empresarial pública. 


\section{Fisura del principio de autonomía de la voluntad en el orden contractual, y la reducción del principio de libre competencia}

Dentro de las manifestaciones antes referidas, de acuerdo a la profesora Arenas Alegría (20l3) se requiere deslindar entre lo que puede denominarse empresa pública concurrencial y empresa pública no concurrencial, es decir aquella empresa pública que acude al mercado compitiendo con otras empresas, lo que hace retornar a lo preceptuado en el artículo 4 literal c de la Ley 550 (2005) al decir que la ley creadora de la empresa pública establecerá los fines específicos para su funcionamiento: servicio público o actividad comercial.

La distinción de fin empresarial como servicio público o actividad comercial encuentra algunas referencias en los siguientes cuerpos normativos:

- Ley 822, Ley de Concertación Tributaria, (2012):

Art. 32: Exenciones subjetivas. Se encuentran exentos del pago del IR de actividades económicas, sin perjuicio de las condiciones para sujetos exentos reguladas en el artículo 33 de la presente Ley, los sujetos siguientes: ... 2. Los Poderes de Estado, Ministerios, Municipalidades, Consejos y Gobiernos Regionales y Autónomos, entes autónomos y descentralizados y demás organismos estatales, en cuanto a sus rentas provenientes de sus actividades de autoridad o de derecho público; (Cursiva es del autor).

- Ley 737, Ley de Contrataciones Administrativas del Sector Público. "Art. 3 Sector Público:... 6. Las Empresas del Estado, salvo cuando estén en situación de competencia...".

Encontrar un criterio que pueda determinar la existencia o no de tales servicios es sumamente complejo, dado la carencia de una definición holística de servicio público, a pesar de que la recién aprobada Ley de Asociación Pública Privada (2016) ofrece un concepto en su art.3 numeral 9, que para este autor es escueto y hasta confuso. Por lo cual es importante tomar en cuenta el criterio utilizado por la legislación y experiencia europea a través de las conclusiones del Abogado General Sr. Stix-Hackl del 7 de noviembre de 2002, al decir que es importante recurrir a los criterios de servicio universal para determinar la existencia de un servicio con fines de intereses general, los cuales son: " a) accesibilidad de los usuarios a tales actividades, b) la obligación de pagar un precio razonable y c) el establecimiento de una garantía de calidad en la prestación del servicio” (STJE de 23 de octubre de 1997).

Con relación a lo anterior, se ha reconocido que el monopolio sobre el establecimiento y la explotación pública de telecomunicaciones constituyen un servicio de interés económico general (Art.9 y 10). En este sentido es importante ubicarse en el tiempo y espacio para el caso de nuestro sistema jurídico, pues en un momento dado el Estado de Nicaragua realizó la provisión de los servicios de telecomunicaciones de telefonía básica lo que justificaría en su momento el dominio exclusivo $^{86}$ del Estado sobre ese servicio, que encuentra asidero legal en lo dispuesto en el art. 4

${ }^{86}$ En la actualidad no existe monopolio en ninguno de los servicios de telecomunicaciones en 
de la Ley No. 200 Ley General de Telecomunicaciones y Servicios Postales que establece que el espectro radioeléctrico, es un bien del dominio público sujeto al control del Estado.

No obstante el quid para determinar la existencia de interés económico general de un servicio en este caso se encuentra en la obligación de efectuar la administración y regulación del espectro radioeléctrico, asignación de frecuencias radioeléctricas y el otorgamiento de licencias para la instalación y operación de estaciones transmisoras (art. 5), con el objetivo de beneficiar a todos los usuarios, a través de precios abordables, respectos de determinados estándares de calidad y no discriminación en la prestación.

Ahora respecto a la posible vulneración de la competencia en el mercado por parte de una empresa pública se puede preguntar si el respeto a esta supone un límite al objeto social de aquella o, dicho de otro modo, si la actividad de la empresa pública debe circunscribirse a la gestión y prestación de actividades de interés general o puede ampliarse a cualquier otra. ¿Empresa pública concurrencial o no concurrencial?.

\section{Breve diagnóstico de la actividad empresarial pública en el ordenamiento jurídico nicaragüense}

El siempre dificultoso fenómeno empresarial como se ha mencionado en líneas anteriores no es lejano a nuestra realidad jurídica. Al igual que la experiencia comparada nuestro sistema presenta grandes desafíos en su reforma práctica y positiva. El siguiente caso denota una perspectiva de como el fenómeno de la dinámica realidad empresarial estatal no encuentra uniformidad en cuanto su positivación y aplicabilidad, y más aún cuando la actividad empresarial pública no es armónica con las demás disposiciones establecidas en el ordenamiento jurídico.

\section{I Caso Produzcamos}

Aspectos preliminares

a) Nombre: BANCO DE FOMENTO A LA PRODUCCIÓN (PRODUZCAMOS).

b) Norma creadora: Ley No. 640, Aprobada el 06 de Noviembre del 2007, publicada en La Gaceta Diario Oficial No. 223 del 20 de Noviembre del 2007.

c) Ámbito de aplicación:

Artículo I. Creación del Banco de Fomento a la Producción. Créase el BANCO DE FOMENTO A LA PRODUCCIÓN que en adelante, para efectos de esta Ley se llamará simplemente BANCO PRODUZCAMOS o PRODUZCAMOS, como una entidad del Estado, con personalidad jurídica y patrimonio propio, de duración indefinida y de plena capacidad para adquirir derechos y contraer

Nicaragua, ya que el período de exclusividad que le brindaba la concesión a ENITEL, ha expirado de conformidad al Decreto No. 136-2004, Política Sectorial y Lineamientos de Apertura del Mercado de Telecomunicaciones, Publicado en La Gaceta Diario Oficial No. 02 del 04 de Enero del 2005. 
obligaciones, respecto de todos aquellos actos o contratos que sean necesarios para el cumplimiento de sus objetivos y regulado por las disposiciones determinadas en esta Ley.

No se aplicará a Produzcamos las disposiciones contenidas en la legislación bancaria referidas a los requisitos y autorizaciones para la constitución e inicios de operaciones de los bancos comerciales. No obstante le serán aplicables las demás disposiciones de la legislación bancaria vigente (Cursiva es del autor).

\section{Consideraciones jurídicas:}

La existencia de bancos estatales encuentra un corto señalamiento en la Ley 290 , que en su artículo 3 de integración del Poder Ejecutivo menciona:

El Poder Ejecutivo está integrado por el Presidente de la República, el Vice-Presidente de la República, Ministerios de Estados, Entes Gubernamentales, Bancos y Empresas Estatales y para el mejor cumplimiento de sus funciones pueden organizarse de forma descentralizada o desconcentrada (Cursiva es del autor).

Posteriormente establece en su artículo 5:

Los Bancos Estatales, las demás instituciones financieras del Estado y otras entidades empresariales del Estado, están regulados por su régimen jurídico.

Los señalamientos antes vertidos, no ofrecen una definición de que es Banco estatal, a pesar que el artículo I de la Ley 640 establece que PRODUZCAMOS es una entidad del Estado, con personalidad jurídica y patrimonio propio, de duración indefinida y de plena capacidad para adquirir derechos y contraer obligaciones.

Dicha definición encuentra ciertas interrogantes, que

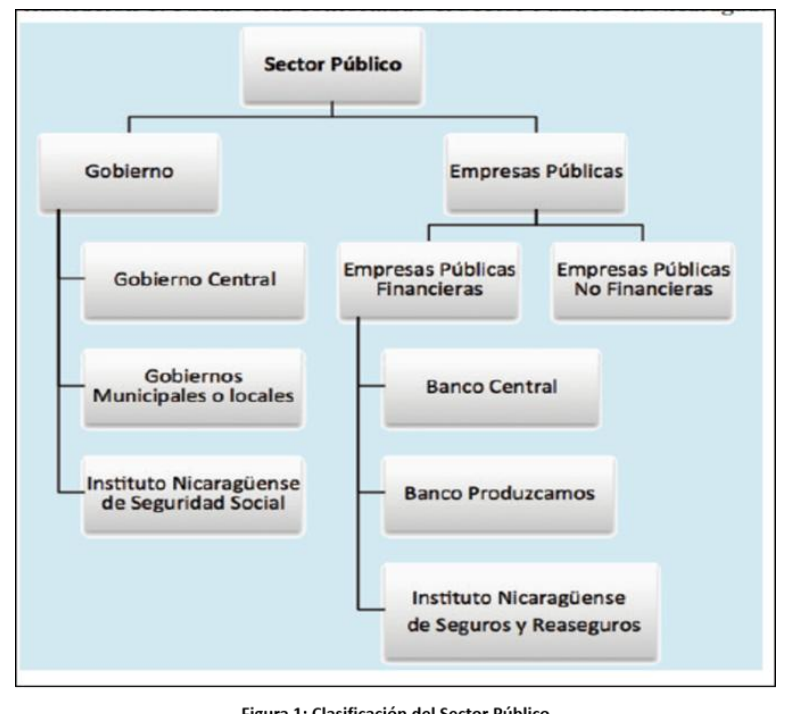

Figura 1: Clasificación del Sector Público son propias en la configuración de la intervención económica del Estado, dado lo siguiente:

La Ley 640 y sus reformas establece que PRODUZCAMOS es una entidad del Estado, pero ¿qué tipo de entidad del Estado? De acuerdo a la Ley 290 en su artículo 3 la integración del Poder Ejecutivo puede estar establecida por: ....Entes Gubernamentales, Bancos y Empresas Estatales..., las cuales pueden organizarse de forma descentralizada o desconcentrada.

En este sentido el Sector Público se clasifica para fines gráficos de la siguiente manera (USAID, s/f). Lo cual hace al caso en análisis a Produzcamos en una entidad empresarial financiera del sector público. Pero parece apuntar que las categorías "ente gubernamental" y "banco" responden a dos 
expresiones distintas de la administración, que pueden organizarse de forma descentralizada o desconcentrada, pero que en el caso en examen no parece tener claridad, dado que la Ley creadora establece que Produzcamos es una entidad del Estado, con personalidad jurídica y patrimonio propio...

A diferencia de lo establecido en la Ley General de Bancos, Instituciones Financieras No Bancarias y Grupos Financieros (Ley 56I) que manifiesta que:

Art. 3. Todo banco que se organice en Nicaragua deberá constituirse y funcionar como sociedad anónima de acuerdo con esta Ley, el Código de Comercio y demás leyes aplicables a este tipo de sociedades en cuanto no estuviesen modificados por la presente Ley (Cursiva es del autor).

También es importante señalar lo preceptuado en el artículo 2 de la Ley 477 "Ley General de Deuda Pública" (2003), que establece:

Para los efectos de esta Ley el sector público comprende:

-Poder Ejecutivo, conforme se define en el artículo 3 de la Ley 290, (Presidencia y Vice Presidencia de la República, Ministerios de Estado, entes gubernamentales que pueden ser descentralizados o desconcentrados, bancos e instituciones financieras del Estado y entidades empresariales del Estado);

Si bien no se aplican a Produzcamos las disposiciones contenidas en la legislación bancaria referidas a los requisitos y autorizaciones para la constitución e inicios de operaciones de los bancos comerciales, es necesario denotar que la misma ley creadora sigue tropezando en el desacierto de no configurar con claridad una entidad empresarial desde su aspecto subjetivo, lo que remarca el criterio de la falta de uniformidad del concepto de empresa y empresa pública en su estricto sentido.

\section{Régimen jurídico aplicable}

De la lectura de la Constitución Política de Nicaragua parece extraerse que el Estado goza en efecto de absoluta libertad en materia de intervención económica; sin embargo son numerosos los asuntos que se plantean sobre la compatibilidad de dichas actividades con la normativa de competencia vigente (Ley 60I, Ley de Promoción de la Competencia, 2006), ya que en muchos casos se cuestiona la verdadera naturaleza de interés general que pudiera tener una actividad ejercida por una empresa pública.

Nuestra legislación de competencia establece que:

Art. I.- Objeto de la Ley. El objeto de la presente Ley es promover y tutelar la libre competencia entre los agentes económicos, para garantizar la eficiencia del mercado y el bienestar de los consumidores, mediante el fomento de la cultura de la competencia, la prevención, la prohibición y sanción de prácticas anticompetitivas (Cursiva es del autor). 
Abarcando en el caso de la manifestación empresarial en estudio establece:

Art. 2.- Ámbito de aplicación. Están sujetos a las disposiciones de esta Ley cualquier acto, conducta, transacción o convenio realizado por los agentes económicos en todos los sectores de la economía nacional, incluyendo los efectos fuera del país, en la medida en que produzcan o puedan producir efectos anticompetitivos en el mercado nacional.

Art. 3.- Definiciones. Agente económico: Toda persona natural o jurídica, sea esta última pública, privada o mixta, o cualquier forma de organización, tenga o no fines de lucro, que realice actividades económicas (Cursiva es del autor).

Esto implica que todo proceso de apertura del mercado a la competencia requiere de una serie de mecanismos de regulación que permitan que las nuevas empresas puedan operar en el mercado sin verse oprimidos por el peso específico de quien, con dinero público, se beneficia de situaciones pasadas (Arenas Alegría, 2013).

Por lo cual la dualidad del régimen jurídico aplicable a la empresa pública dada su naturaleza, presenta un interesante marco regulatorio con relación a su creación, funcionamiento, modificación y extinción de la misma en nuestro ordenamiento. Tanto así que la técnica legislativa al respecto ha variado, generando ciertas imprecisiones en cuanto al régimen existente.

\section{7.l. Régimen jurídico de la contratación administrativa en las empresas públicas y replanteamiento}

La contratación por parte del sector público ha sido un tema de constante discusión en la coyuntura social, económica, política y sobre todo jurídica, dada la controversia en los procedimientos aplicables y las materias excluidas a esos procedimientos de contratación, dado a factores como la corrupción, tráfico de influencias, cohecho, etc.

Ciertamente el ordenamiento jurídico patrio antes de la entrada en vigencia de la Ley 737 "Ley de Contrataciones Administrativas del Sector Público" (2010), contaba con una norma contrataciones del sector público (Ley No. 323, 2000) que manifestaba esa potestad de iniciativa pública económica del Estado, presentando disparidades conceptuales del siempre vivo fenómeno empresarial, en el caso particular la actividad empresarial del Estado.

Ejemplo de ello es que en su artículo 2 se establecía que el ámbito de aplicación era: “...10. Todas aquellas Instituciones o Empresas que reciben fondos provenientes del Sector Público o en las que el Estado tenga participación accionaria” (Ley No. 323, 2000).

En el caso de la Ley de Contrataciones del Sector Público vigente (Ley 737, 2010), esta reza que: 
Art. I. La presente Ley tiene por objeto establecer el régimen jurídico, sustantivo y procedimental, aplicable a la preparación, adjudicación, ejecución y extinción de las contrataciones administrativas, celebradas por los organismos y entidades que forman parte del Sector Público.

La presente Ley es de orden público, por lo tanto, las partes que intervienen no podrán alterar los procedimientos ni renunciar a los derechos establecidos en la presente Ley. En ningún caso, la naturaleza de un contrato dependerá de su denominación formal, convenida por las partes o impuesta por una de ellas.

Tenor que indica que el régimen jurídico aplicable a todo el procedimiento de contratación del sector público es la ley mencionada; sin embargo para el caso de las empresas públicas, la misma ley hace una regulación muy particular y a la vez peligrosa del régimen de contratación aplicable en el tenor del artículo 2 numeral 6. Peligrosidad que radica en la potestad de la Dirección General de Contrataciones al momento de establecer los lineamientos que seguirán las empresas del dominio del Estado a través del manual de contrataciones de régimen especial que se autorice.

Ejemplo de esto es la supresión o posibilidad de no exigir en las contrataciones que realicen las garantías económicas que protejan al Estado, o realizar compras directas de forma más ágil vulnerando el principio de transparencia y libre competencia (Véase el caso de la publicación hecha por La Prensa sobre el Manual de contrataciones de EPN http://www.laprensa.com.ni/2016/03/14/reportajes-especiales/2001017-empresas reaccionan-acontratos-de-la-portuaria).

Estudio evidentemente que puede prestarse a un mayor campo de análisis, pero que a todas luces encuentra los mismos tropiezos ya señalados con relación a establecer un criterio armónico sobre que es empresa pública, fundamentos de intervención, clasificación y su régimen jurídico aplicable.

Esta cuestión por ejemplo en la experiencia jurídica comparada se debatió y resolvió por el Tribunal de Justicia Europeo en la Sentencia SIEPSA (STJE S I6-10-2003, № C-283/2000) manifestando que el hecho de que la empresa pública obtenga un beneficio y que realice transacciones para generar beneficios supone que se encuentra ante una actividad típicamente mercantil, que sólo puede llevarse a cabo por una sociedad sujeta al juego de las normas mercantiles del sector privado, con el que necesariamente ha de entrar en contacto.

Dado que sí el fin de la empresa pública es simplemente actuar en el mercado como un empresario más (lo que por otro lado justificaría su régimen privado) es, no sólo indiferente, sino contraproducente que el objeto de la actividad desarrollada se conecte directamente con el interés general. Si por el contrario el fin de la empresa pública radica en satisfacer necesidades no cubiertas por el sector privado asegurar la competencia o corregir defectos en el mercado, es evidente que en sí misma la empresa pública se conecta con la satisfacción del interés general. Y si es así ¿es correcto que actúe a la manera y con las armas del derecho privado? 
Lo que haya de cierto en estas ideas choca frontalmente con el aforismo de que "la Administración dispara siempre con pólvora del Rey” (Arenas Alegría citando a De Ramon, 2013, p.40). Además una expansión excesiva del sector público hacia cualquier actividad pudiera suponer un peligro para derechos y libertades ciudadanas llegando a manipular el mercado, por su nivel de intervención en otras instituciones que conforman la Administración (Aduanas, Puertos, almacenes, etc.).

Esto puede ser ilustrado con el caso peruano donde el Ministerio de Transportes, reportó que el Ejército controlaba alrededor de 20 plantas de asfalto e innumerable maquinaria y equipo adquirido con recursos del tesoro, las mismas que se usan para competir con el sector privado en la construcción de carreteras en todo el país. Su capacidad es incluso mayor a la del sector privado para hacer la misma labor, desplazándola prácticamente de esta actividad. El presupuesto para 1999 de estas plantas, superaron los US\$ 170 millones y el número de maquinaria estimada existente en estas plantas es de I,500 máquinas, según el Ministerio de Transportes (Ministerio de Economía y Finanzas, Perú, s/f).

Por ello replantear el estudio y aplicación de la actividad empresarial del Estado en nuestro país, requiere revisar los escenarios propuestos por el Banco Mundial en el año de 1997 sobre las funciones del Estado donde expone como máxima de aplicación para un Estado Moderno las Funciones activas que corresponden a la actividad empresarial representativa, introducida constitucionalmente por la definición de economía mixta (art.104 Cn) y ejercida desde distintas formas de manifestaciones empresariales, dada la carente regulación armónica del siempre vivo fenómeno empresarial, que se traslada a la misma actividad empresarial del Estado.

Por ello el replanteamiento podría fijarse en los siguientes elementos de análisis:

a) Una definición integral de empresa: La propuesta de definición que ofrece el Anteproyecto de Código Mercantil sobre empresa puede ser una alternativa para definirla bajo una perspectiva integral, al considerarla el medio compuesto por elementos dinámicos de personal, capital, materiales y técnica, que organiza la persona empresaria individual o jurídica como una unidad específica destinada a desarrollar una o varias actividades del giro del negocio de la persona empresaria (Artículo VII. Párrafo $5^{\circ}$ ).

b) Una definición de empresa pública: El éxito de lograr definir una empresa pública podría estar dado en torno de dos elementos: La existencia de una empresa y la adjetivación de la misma como pública y sus alcances.

c) Régimen de Contratación: El replanteamiento del régimen jurídico de la contratación administrativa para las empresas públicas podría encontrar respuesta en la configuración de una norma de contrataciones para empresas del sector público, distinta a la norma de contrataciones del sector no empresarial, fijando como elementos de ordenación la agilización de los procedimientos a fin de garantizar que la misma se ajuste a los principios de libertad de acceso a las licitaciones, publicidad y transparencia de los procedimientos, y no discriminación e igualdad de trato entre los candidatos, y de asegurar, en conexión con el objetivo de estabilidad presupuestaria, control del gasto y no endeudamiento público, 
una eficiente utilización de los fondos destinados a la realización de obras adquisición de bienes y la contratación de servicios mediante la exigencia de la definición previa de las necesidades a satisfacer, que estará en conexión directa con la concurrencialidad de la actividad económica pública propia de la discusión legislativa, siempre que se salvaguarde la libre competencia y la selección de la oferta económicamente más ventajosa.

d) Gobernanza de las empresas públicas: La administración de las empresas públicas puede encontrar solución bajo la aplicación efectiva de los principios de Gobierno Corporativo teniendo como puntos de partida una estructura de gestión sólida, información del desempeño de las actividades, concordancia y controles en la gestión, gestión del riesgo de las políticas de inversión, estrategia y planeación de políticas consensuadas, y valores sobre la base de un Código de ética.

\section{Conclusiones}

De la exposición situada en líneas anteriores, sobre las situaciones jurídicas controvertidas que presenta la legislación nicaragüense con relación a las empresas públicas en su forma de conceptualización, configuración, modificación, ámbito de aplicación y extinción, dentro de la intervención representativa económica se lograr concluir:

I. La posición jurídica equivalente de la iniciativa económica privada y la pública, significa que ambas deben de actuar en el mercado respetando las complejas reglas del mismo y que es sólo, incidiendo en esa complejidad, que los poderes públicos deben de procurar la consecución de las exigencias del Estado social.

2. No es preciso buscar un específico fallo en el mercado para justificar la actuación de la iniciativa económica pública, ya que en el caso patrio existe base constitucional suficiente para introducir sin ulteriores matices al Estado en la economía como un agente más. (Véase Art. 5, 98 y $104 \mathrm{Cn}$.)

3. En nuestro Derecho patrio la expresión "empresa" al igual que "empresa pública" es una categoría doctrinal, que encuentra pequeñas referencias en cuerpos normativos como la Ley $N^{\circ}$ 550, Ley de Administración Financiera y del Régimen Presupuestario, (2005), Ley 737, Ley de Contrataciones Administrativas del Sector Público, (2010), Ley 838, Ley General de Puertos de Nicaragua, (2013), entre otras.

4. La empresa pública es un organismo económico, coordinador de diversos elementos y bienes del Estado para producir bienes o servicios. Su carácter económico, que traduce la palabra empresa, exige su autonomía frente al Estado, pero la palabra pública debe traducirse en obediencia al Estado, quien la controlará y llevará su dirección.

5. La empresa pública debe poseer personalidad jurídica derivada expresamente de la Administración Pública, y no utilizar la misma, dado que es necesario que la voluntad representativa del Estado (Asamblea Nacional) derive solemnemente la personalidad jurídica de la Administración desde su aspecto interno para poder permitir que la misma Administración intervenga de forma directa en la economía. 
6. De la lectura de la Constitución Política de Nicaragua parece extraerse que el Estado goza en efecto de absoluta libertad en materia de intervención económica. No obstante la libertad de empresa, como cimiento toral del orden constitucional y derecho subjetivo garantizado por la misma, no implica que el legislador constituyente patrio haya optado por privilegiar de forma absoluta a la iniciativa privada sobre la iniciativa pública, ya que la misma Constitución ha introducido un concepto como es la economía mixta (art.104 Cn) que involucra la función social como modulador de la libertad de empresa, trayendo como resultado la concreción del reconocimiento de la propiedad privada en el sector empresarial, y la intervención representativa del Estado en la economía como garante del principio de libertad de empresa, o su presupuesto fundamental, la libre competencia.

7. Nuestro ordenamiento jurídico no se aparta de la posición jurídica de no encontrar fórmulas normativas consensuadas con relación a la empresa pública, produciendo complejidad al momento de establecer los lineamientos técnicos jurídicos en el cual han de fundarse los procedimientos de creación, desarrollo, organización, control, modificación y extinción de la empresa pública, pues nuestro ordenamiento jurídico vislumbra a la empresa pública más como un concepto económico y no jurídico.

8. La falta de armonicidad en el régimen jurídico de la empresa pública en el ordenamiento nicaragûense responde al siempre vivo fenomeno empresarial, por lo cual se requiere replantear el sistema normativo existente, con el fin de que cree, configure, modifique, extinga y limite la actividad empresarial del Estado, basando el replanteamiento en los criterios de servicio universal de interés público.

9. El replanteamiento podría iniciar en la configuración de una norma orgánica de empresas públicas que permita establecer los elementos necesarios de la actividad empresarial pública. Elementos como conceptualización, ámbito de aplicación, clasificación, formas de intervención, áreas de intervención, administración y formas de extinción.

10. La concurrencialidad de la actividad de la empresa pública pertenece a una concepción dualista de los actos de la Administración en el mercado, que se establece por realidad jurídica positiva, que en el caso nicaragüense encuentra una pequeña referencia en el artículo 4 literal c de la Ley 550. Por lo tanto se hace inexcusable para un replanteamiento sano, trazar en el regazo de la labor doctrinal y legislativa la existencia de actos administrativos de objeto privado que aparecen con mayor gravitación evidentemente en las entidades empresariales del dominio del Estado, tomando como partida la existencia del planteamiento constitucional de mercados integrados en economía mixta y libertad empresarial.

II. El replanteamiento del régimen jurídico de la contratación administrativa para las empresas públicas podría encontrar respuesta en la configuración de una norma de contrataciones para empresas del sector público, distinta a la norma de contrataciones del sector no empresarial, fijando como elementos de ordenación la agilización de los procedimientos a fin de garantizar que la misma se ajuste a los principios de libertad de acceso a las licitaciones, publicidad y transparencia de los procedimientos, que estará en conexión 
directa con la concurrencialidad de la actividad económica pública en la discusión legislativa, siempre que se salvaguarde la libre competencia y la selección de la oferta económicamente más ventajosa.

12. El umbral existente entre la actividad empresarial pública y la transgresión a la libre competencia es mínima, por lo cual se requiere replantear en el seno de la labor legislativa criterios, como los de satisfacción universal, sobre a qué sectores de intervención económica el Estado debe acudir, para de esta manera lograr armonicidad en el mercado.

13. Es innegable que la intervención representativa del Estado en la economía es parte de la dinámica realidad empresarial, que encuentra suficiente justificación constitucional para su participación en la economía. A pesar de encontrar detractores, es una realidad juridica que debe de ser asimilada y replanteada en los aspectos de configuración normativa y aplicabilidad; replanteamiento que debe surgir en el seno de la labor doctrinal y legislativa para propiciar el equilibrio entre los agentes económicos (públicos y privados) y las complejas reglas del mercado.

\section{Lista de referencias}

Alonso Ureba, A. (1985). La empresa pública. Madrid. Extraído de la base de datos Vlex.com Areas Alegría, C. (20I3). El sector público económico de ámbito estatal: su régimen jurídico y actual. Extraído de la Base Vlex.com con fecha II/03/2016.

Areas Alegría, C. (2013). Las sociedades públicas, Régimen Jurídico y el replanteamiento actual. Ed. Dykinson. Madrid. Extraído de la base de datos Vlex.com

Asamblea Nacional. (1995). Ley N²00. Ley General de Telecomunicaciones y Servicios Postales. Publicada en La Gaceta Diario Oficial N 154 el día 18 de Agosto de 1995.

Asamblea Nacional. (1996). Ley N 185. Código del Trabajo. Publicada en La Gaceta Diario Oficial No. 205, del 30 de Octubre de 1996, y sus reformas.

Asamblea Nacional. (1999). Ley No. 323. Ley de Contrataciones del Estado. Publicada en La Gaceta Diario Oficial Nos. 001 y 002 del 3 y 4 de Enero del 2000.

Asamblea Nacional. (2003). Ley $N^{\circ}$ 477. Ley General de Deuda Pública. Publicada en La Gaceta Diario Oficial $N^{\circ} 236$ del día 12 de diciembre de 2003.

Asamblea Nacional. (2005). Ley $\mathrm{N}^{\circ}$ 550. Ley de Administración Financiera y del Régimen Presupuestario. Publicada La Gaceta Diario Oficial $N^{\circ}$ 167, el día lunes 29 de agosto de 2005.

Asamblea Nacional. (2006). Ley $N^{\circ}$ 60I. Ley de Promoción de la Competencia. Publicada en La Gaceta Diario Oficial N²06 el día 24 de octubre de 2006.

Asamblea Nacional. (2007). Ley $N^{\circ}$ 606. Ley Orgánica del Poder Legislativo de la República de Nicaragua. Publicada en La Gaceta Diario Oficial No. 26 del 06 de Febrero del 2007

Asamblea Nacional. (2007). Ley No. 640. Ley creadora del Banco de Fomento a la Producción (Produzcamos). Publicada en La Gaceta Diario Oficial No. 223 del 20 de Noviembre del 2007. Asamblea Nacional. (2009). Ley No. 698. Ley General de los Registros Públicos Publicada en La Gaceta Diario Oficial No. 239 del 17 de diciembre del 2009. 
Asamblea Nacional. (2010). Ley 737. Ley de Contrataciones Administrativas del Sector Público. Publicada La Gaceta Diario Oficial N²0I3, publicada el día lunes 8 de noviembre de 2010. Asamblea Nacional. (2012). Ley 822. Ley de Concertación Tributaria. Publicada en La Gaceta Diario Oficial $\mathrm{N}^{\circ} 24 \mathrm{I}$, el día lunes 17 de Diciembre de 2012

Asamblea Nacional. (2013). Ley No 838. Ley General de Puertos de Nicaragua. Publicada en La Gaceta Diario Oficial No 92, el día 2l de mayo de 2013.

Asamblea Nacional. (20I4). Constitución Política de la República de Nicaragua. Publicada en La Gaceta Diario Oficial No. 32 del 18 de febrero del 2014.

Asamblea Nacional. (2015). Ley $N^{\circ}$ 290. Ley de Organización, Competencia y Procedimientos del Poder Ejecutivo. Publicada en La Gaceta Diario Oficial $N^{\circ} 35$, el día Viernes 22 de febrero de 2015 .

Asamblea Nacional. (2016). Ley 935. Ley de Asociación Público Privada. Publicada en La Gaceta Diario Oficial $\mathrm{N}^{\circ}$ 9I del 12 de octubre de 2016.

Barcelata Chávez, H. (1997). Intervencionismo Estatal y Economía Mixta. Revista Economía № I, Vol. I. Facultad de Economía, UV, Xalapa.

Barrera Zapata, R. (1998). Desregulación, simplificación y nueva técnica en el servicio público. Gaceta Mexicana de Administración Pública Estatal y Municipal. № 61 . Extraído de la página web http://biblio.juridicas.unam.mx/libros el día 28/04/2016.

Campos Fernández, S. (2013). Las empresas de Derecho Público en el Sistema Registral peruano. Zona

Registral $N^{\circ}$ IX-Sede Lima. www.derechoycambiosocial.com

Castro Estrada, J. (2002). La teoría del servicio público en el derecho Mexicano. Colección Facultad de Derecho. ISB9703201555. Extraído de la página web http://biblio.juridicas.unam.mx/libros el día 28/04/2016

Código Civil de la República de Nicaragua. Publicado en La Gaceta Diario Oficial No. 2I48 del 5 de febrero de 1904. Nicaragua.

Derecho Comunitario Europeo, Directiva 80/732/CE, 25 de junio de 1980.

Eto Cruz, G. (s/f). Horizontes contemporáneos del Derecho Procesal Constitucional.

Hernández, J. (2010). La regulación económica de actividades de interés general y la vuelta al modelo estatitas. Ed. Palestra. Extraído de la base de datos Vlex.com.

López Guerra, L. (1980). Sobre la Personalidad Jurídica del Estado. Revista del Departamento de Derecho Político Núm. 6. Primavera 1980.

Ministerio de Economía y Finanzas (S/f). Sobre los mecanismos para evitar la Competencia Desleal del Estado: Capítulo IV. Perú. Extraído el día 02/06/2016 del sitio web http://www.mef.gob.pe/index.php?option=com_content\&view=article\&id=21 19\%3Asobrelos-mecanismos-para-evitar-la-competencia-desleal-del-estado-capituloiv\&catid $=297 \&$ Itemid $=101004 \&$ lang $=$ es

Ministerio de Fomento Industria y Comercio. (2015). Anteproyecto de Código Mercantil de la República de Nicaragua. www.mific.gob.ni/LinkClick.aspx?fileticket=7nD8G7qR_MA\%3D\&tabid.

Morales, F. (1990). La empresa pública en América Latina, origen, desarrollo y crisis: el caso de chile. Revista de Administración Pública. $N^{\circ} 77$, sección de Tribuna.

Nava Negrete, A. (1965). Empresa pública y Sociedad Anónima de Estado. Revista de la Facultad de Derecho de México. T. XV. Nº 57. 
Rad Bruch, G. (1962). Arbitrariedad legal y derecho supralegal. Buenos Aires, Abeledo-Perrot, trad. de M. I. Azaretto de Gesetzliches Unrecht und übergesetzliches Recht.

Rojas Mercado, R. (2010). La empresa como objeto de negocios jurídicos: énfasis en la compraventa de empresas. Revista de Derecho, Universidad Centroamericana. UCA. $2^{\mathrm{a}}$ época.

Sentencia del Tribunal de Justicia (STJCE) Sala 6 ${ }^{a}$, S 16-10-2003, N C-283/2000.

Sentencia del Tribunal de Justicia (STJCE) Sala 6a , S 16-10-2003, N C-283/2000.

Sentencia No. 03 Corte Suprema de Justicia (SCJN).- Managua, veinticinco de enero del año dos del año dos mil once. Las once y tres minutos de la mañana.

Sentencia Tribunal Constitucional Español (STCE) 88/196, I de Julio.

Sentencia Tribunal Jurisdicción Europea (STJE) de 23 de octubre de 1997. Stix-Hackl del 7 de noviembre de 2002

Sentencia Tribunal Jurisdicción Europea (STJE) de 10 de diciembre de 1991, Merci convenzionali porto di Genova SpA c.Siderurgica Gabrielli SpA, C-I79/90

Suan Rodríguez, C. (1993). La empresa pública bajo forma societaria. ¿Supone su régimen, jurídico una derogación del derecho común de sociedades? El problema de su control. Extraído de la base de datos Vlex.com. 